Research Article

\title{
Method for Determining Longitudinal Stiffness of Combined Double Thin-Walled Pier Based on Train-Track-Bridge Interaction
}

\author{
Hui Fang' and Zhaowei Chen $\mathbb{1}^{2,3}$ \\ ${ }^{1}$ State Grid Chongqing Electric Power Research Institute, Chongqing, China \\ ${ }^{2}$ School of Mechanotronics \& Vehicle Engineering, Chongqing Jiaotong University, Chongqing, China \\ ${ }^{3}$ T. Y. Lin International Engineering Consulting (China) Co., Ltd, Chongqing, China
}

Correspondence should be addressed to Zhaowei Chen; chenzhaowei@my.swjtu.edu.cn

Received 2 February 2020; Accepted 22 April 2020; Published 25 May 2020

Academic Editor: Daniele Baraldi

Copyright (c) 2020 Hui Fang and Zhaowei Chen. This is an open access article distributed under the Creative Commons Attribution License, which permits unrestricted use, distribution, and reproduction in any medium, provided the original work is properly cited.

\begin{abstract}
Combined double thin-walled pier is a new kind of pier adopted in the urban transit system in China, whose longitudinal stiffness cannot be determined by adopting traditional methods. Aiming at this practical issue, this work proposed an alternative method for determining the longitudinal stiffness of the combined double thin-walled pier based on the train-track-bridge interaction. Primarily, the relationship between longitudinal stiffness of the pier and rail stress is underlined, based on which the proposed methodology is described in detail. Finally, a case study is conducted to validate the effectiveness of the proposed method. Results show that the train-track-bridge dynamic interaction theory is effective in determining the longitudinal stiffness of the newly designed and special pier. Rail stress and longitudinal displacement of pier top exceed their limit values with the change of pier longitudinal stiffness. The dynamic stress and thermal stress of rail are the two most important indicators in determining pier longitudinal stiffness, which should be paid attention to in practical engineering.
\end{abstract}

\section{Introduction}

Due to the good mechanical performance and artistic appearance, a new kind of pier, namely, combined double thinwalled pier (CDTWP, as seen in Figure 1), is recently designed in a long-span rigid frame bridge in China's rail transit system. CDTWP consists of two parts, i.e., the common hollow pier with high stiffness (lower part) and the double thin-walled pier with low stiffness (upper part), making the mechanical performance of this combined structure complicated. Longitudinal stiffness is a key parameter in designing CDTWP. The larger the longitudinal stiffness is, the bigger the pier is and the heavier the structure is. Otherwise, if the stiffness is too small, the stability of the superstructure cannot be ensured. Hence, it is extremely important to determine a reasonable stiffness of CDTWP. However, the existing method for designing stiffness of the traditional hollow/thin-walled pier is not suitable for CDTWP due to the sharply changed cross-sections and composite structure; thus, an alternative method for determining longitudinal stiffness of CDTWP is urgently needed in practical engineering.

Some scholars have focused on pier stiffness for some time. For instance, considering the soil-structure interaction, Chaudhary presented an investigation on the influence of pier stiffness degradation on the seismic behaviors of multispan continuous base-isolated bridges in Japan, in which the stiffness degradation was simulated as change of stiffness [1]. Focusing on a four-span continuous bridge, Chen et al. studied the effect of pier stiffness on the bridge regularity in transverse direction [2]. Stuedlein et al. conducted an analysis of footing load tests on an aggregate pier reinforced clay by changing pier stiffness [3]. Using a nonlinear time history analysis, Wei studied the effects of 


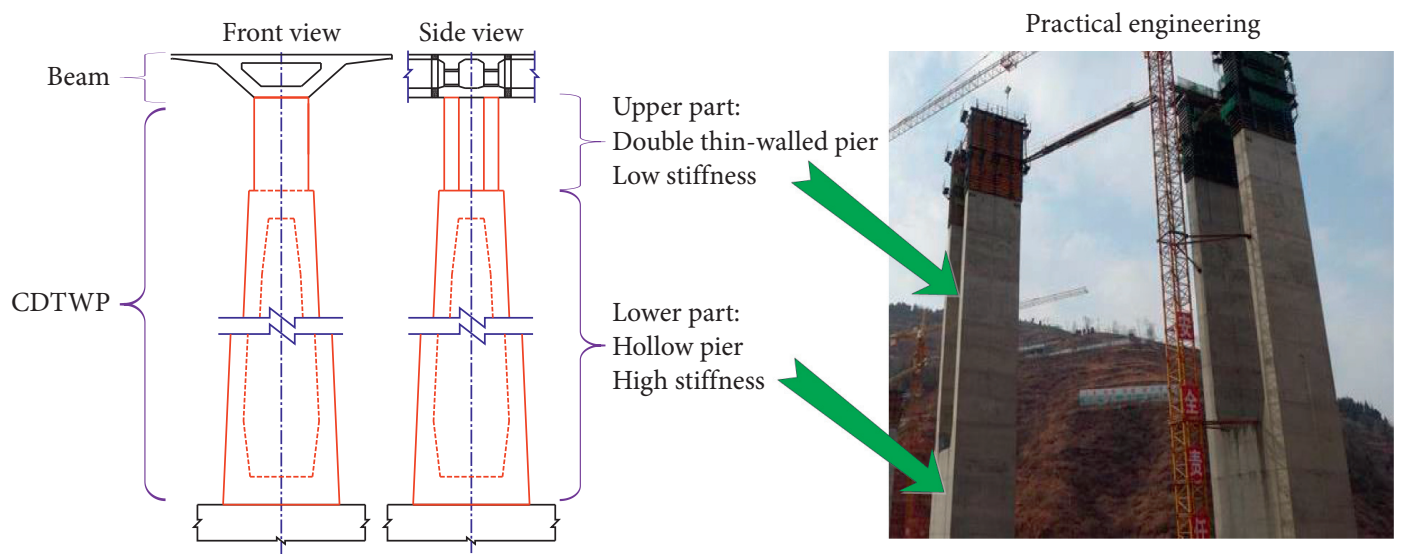

FIgure 1: Combined double thin-walled pier (CDTWP).

pier stiffness on the seismic response of continuous bridges with irregular configuration, based on which a range of the relative column stiffness of two adjacent piers was proposed [4]. Roh et al. proposed an alternative modeling technique for posttensioned rocking bridge piers connected with energy dissipation bars and investigated the effect of yielding strength level and postyielding stiffness ratio of energy dissipation bars on the seismic response of posttensioned rocking bridge piers [5]. To understand the failure mechanism, the energy dissipation capacity, and the hysteretic behavior of the CFST battened built-up column pier, a total of seven test specimens subjected to lateral cyclic repeated loading were tested by Yuan et al. [6]. Shen et al. established both two-dimensional (2D) and three-dimensional (3D) numerical analyses to evaluate the performance of geosynthetic-reinforced soil piers [7]. Moreover, Pollino and Bruneau [8], Olmos and Astiz [9], Huang et al. [10], Chen et al. [11], and so on have also done valuable works on pier stiffness from different aspects. However, almost no research paid attention to the determination of reasonable longitudinal stiffness of new kinds of piers, which is indeed required for engineers.

Aiming on the new designed pier, combined double thin-walled pier, this work presents a framework on the method for determining its longitudinal stiffness based on the train-track-bridge interaction. Primarily, the relationship between longitudinal stiffness of CDTWP and rail stress is underlined, based on which the proposed methodology is described in detail. Adopting the presented method, a numerical case is conducted in the next part. Further some interesting conclusions are drawn in the last section.

\section{Method for Determining Longitudinal Stiffness of Double Thin-Walled Pier Based on Train-Track-Bridge Interaction}

As clearly written in China's published code 'Code for design of urban rail transit bridge (GB/T 51234-2017)', the longitudinal stiffness of the pier (LSP) is designed to achieve two purposes: (a) Ensure the safe operation of rails. If the LSP is too small, the movement of the bridge beam under different loads would be big enough to break the rails.

(b) Ensure the longitudinal displacement of pier top changes in a safe range.

Some limit values of LSP for traditional piers are also suggested in this code (Table 1), while these values are not accurate enough for special and newly designed piers and also not suitable for long-span bridges. On this basis, an alternative method for determining longitudinal stiffness of CDTWP is proposed based on the train-track-bridge dynamic interaction theory in this present work.

The methodology is displayed in Figure 2. As seen from the method, the following two important issues should be seriously considered to obtain the accurate LSP for CDTWP:

(a) Establish an accurate train-track-bridge dynamic interaction model, as described in Section 2.1.

(b) Calculate rail stress caused by different factors, including dynamic effect, temperature effect, and braking effect, as presented in Section 2.2.

2.1. Train-Track-Bridge Dynamic Interaction Model. A detailed train-track-bridge dynamic model is established based on the train-track-bridge dynamic interaction theory [12], which consists of three submodels of the train, the track, and the bridge, as seen in Figure 3. The train, the track, and the bridge are regarded as an integrated dynamic system, in which the train and the track are coupled by the wheel-rail interactive relationship, and the track and the bridge are linked through the track-bridge interaction.

The vehicle model is established based on the multibody system dynamics. The model of a high-speed train consists of seven rigid bodies, including the car body, bogies, wheelsets, and primary and secondary suspensions. Five degrees of freedom (DOFs) are taken into consideration for each rigid body, describing vertical, lateral, roll, yaw, and pitch motions. In total, each vehicle model has 35 DOFs. 
TABLE 1: Suggested values of LSP in the current code.

\begin{tabular}{lc}
\hline Span length $(\mathrm{m})$ & Minimum LSP $(\mathrm{kN} / \mathrm{cm})$ \\
\hline$L \leq 20$ & 190 \\
$20<L \leq 30$ & 240 \\
$30<L \leq 40$ & 320 \\
\hline
\end{tabular}

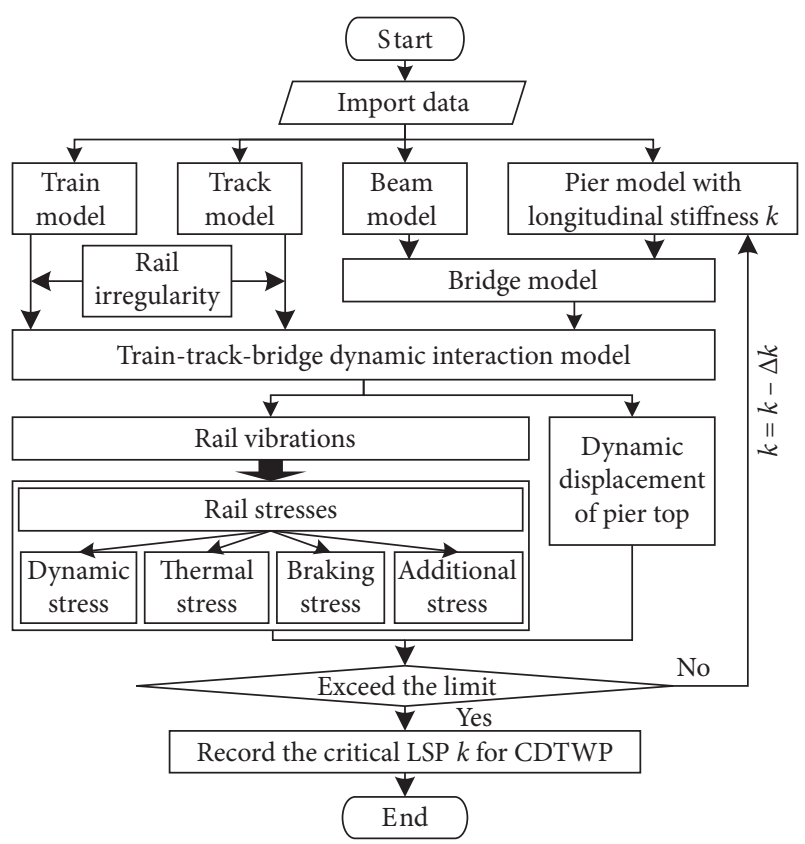

Figure 2: Methodology of determining LSP for CDTWP.

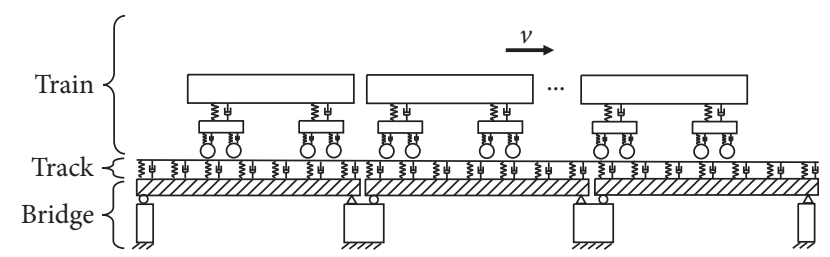

Figure 3: Dynamic model of the train-track-bridge coupled system.

The rail is modeled as a continuous rail beam discretely supported by fasteners, and three DOFs of the rail are taken into account, including vertical, lateral, and torsional vibration.

The bridge is modeled with the finite element method. For different types of bridge structures, the spatial beam element, the spatial pole element, the plate element, and other special elements are used for modeling specific components.

In the established high-speed train-track-bridge dynamic interaction model, the wheel-rail spatially dynamic coupled model is adopted to calculate the wheel-rail contact geometry and contact forces. For the track-bridge dynamic interaction model, the track-bridge interaction forces are different when different types of track structures are adopted.
The detailed information of the established train-trackbridge coupled dynamic model can be referred to the author's published works $[13,14]$, in which the equations of motion for different subsystems, the wheel-rail dynamic interaction, the track-bridge dynamic interaction, and the numerical integration solution are presented.

2.2. Method for Investigating Rail Stress. As seen from the methodology in Figure 2, the rail stresses consist of dynamic stress, thermal stress, braking stress, and additional stress according to the published code 'Code for Design of Railway Continuous Welded Rail (TB 10015-2012)'. The calculations of these different kinds of stresses are presented in this part, and relevant notations are listed in Table 2.

2.2.1. Dynamic Stress of Rail Bottom. Dynamic stress of the rail bottom is caused by rail deflection when trains are running through. The rails are modeled as Euler beams and discretely supported by fasteners which are simulated as linear spring-damping elements. Three DOFs of each rail are taken into account, describing vertical motion, lateral motion, and torsional motion, and the equations of motion of the rail are given as follows:

Vertical motion:

$$
\begin{aligned}
E I_{y} \frac{\partial^{4} z_{\mathrm{r}}(x, t)}{\partial x^{4}}+m_{\mathrm{r}} \frac{\partial^{2} z_{\mathrm{r}}(x, t)}{\partial t^{2}}= & -\sum_{i=1}^{N_{\mathrm{s}}} F_{\mathrm{rV} i}(t) \delta\left(x-x_{i}\right) \\
& +\sum_{j=1}^{N_{\mathrm{w}}} P_{j}(t) \delta\left(x-x_{\mathrm{w} j}\right) .
\end{aligned}
$$

Lateral motion:

$$
\begin{aligned}
E I_{z} \frac{\partial^{4} y_{\mathrm{r}}(x, t)}{\partial x^{4}}+m_{\mathrm{r}} \frac{\partial^{2} y_{\mathrm{r}}(x, t)}{\partial t^{2}}= & -\sum_{i=1}^{N_{\mathrm{s}}} F_{\mathrm{rL} i}(t) \delta\left(x-x_{i}\right) \\
& +\sum_{j=1}^{N_{\mathrm{w}}} Q_{j}(t) \delta\left(x-x_{w j}\right) .
\end{aligned}
$$

Torsional motion:

$$
\begin{aligned}
G J_{\mathrm{t}} \frac{\partial^{2} \phi_{\mathrm{r}}(x, t)}{\partial x^{2}}+\rho_{\mathrm{r}} I_{\mathrm{r} 0} \frac{\partial^{2} \phi_{\mathrm{r}}(x, t)}{\partial t^{2}}= & -\sum_{i=1}^{N_{\mathrm{s}}} M_{\mathrm{F} i}(t) \delta\left(x-x_{i}\right) \\
& +\sum_{j=1}^{N_{\mathrm{w}}} M_{\mathrm{w} j}(t) \delta\left(x-x_{\mathrm{w} j}\right) .
\end{aligned}
$$


TABLe 2: Notations adopted in calculations.

\begin{tabular}{|c|c|}
\hline Notation & Description \\
\hline$\sigma_{\mathrm{d}}$ & Maximum dynamic stress of the edge of rail bottom \\
\hline$\sigma_{\mathrm{t}}$ & Thermal stress of rail \\
\hline$\sigma_{\mathrm{b}}$ & Braking stress of rail \\
\hline$\sigma_{\mathrm{a}}$ & Additional stress of rail caused by deformation of CDTWP \\
\hline$z_{\mathrm{r}}(x, t) / y_{\mathrm{r}}(x, t) / \phi_{\mathrm{r}}(x, t)$ & Vertical/lateral/torsional displacements of the rail \\
\hline$m_{\mathrm{r}}$ & Rail mass per unit length \\
\hline$\rho_{\mathrm{r}}$ & Rail density \\
\hline$E I_{y} / E I_{z}$ & Rail bending stiffness to $Y$-axle $/ Z$-axle \\
\hline$I_{\mathrm{r} 0}$ & Torsional inertia of the rail \\
\hline$G J_{t}$ & Rail torsional stiffness \\
\hline$F_{\mathrm{rV} i}(t) / F_{\mathrm{rLi}}(t)$ & Vertical/lateral dynamic forces of the $i$ th fastener \\
\hline$P_{j}(t) / Q_{j}(t)$ & The $j$ th wheel-rail vertical/lateral forces \\
\hline$M_{\mathrm{Fi} i}(t)$ & Moment applying on rail due to forces $f_{\mathrm{rvi}}(t)$ and $f_{\mathrm{rl} i}(t)$ \\
\hline$M_{\mathrm{w} j}(t)$ & Moment applying on rail due to forces $P_{j}(t)$ and $Q_{j}(t)$ \\
\hline$N_{\mathrm{s}} / N_{\mathrm{w}}$ & Number of fasteners/wheelsets \\
\hline$\delta(x)$ & Dirac delta function \\
\hline$F_{\mathrm{rV} 1 i}(t) / F_{\mathrm{rV} 2 i}(t)$ & Vertical/lateral fastener force acting on the left side of the rail \\
\hline$a_{\mathrm{r}}$ & Vertical distance between rail torsional centre and lateral fastener force \\
\hline$b_{\mathrm{r}}$ & Half of the distance between $f_{\mathrm{rv} 1 i}(t)$ and $f_{\mathrm{rv} 2 i}(t)$ \\
\hline$h_{\mathrm{r}}$ & Vertical distance from rail torsional centre to lateral wheel-rail force \\
\hline & Lateral distance from rail torsional centre to vertical wheel-rail force \\
\hline$Z_{k}(x) / Y_{k}(x) / \Phi_{k}(x)$ & Rail vertical/lateral/torsional mode function \\
\hline$M_{z} / M_{y}$ & Moments of rail \\
\hline
\end{tabular}
by

The moments $M_{\mathrm{Fi}}(t)$ and $\mathrm{M}_{\mathrm{wj}}(t)$ can be further calculated

$$
\left\{\begin{array}{l}
M_{\mathrm{F} i}(t)=\left[F_{\mathrm{rV} 2 i}(t)-F_{\mathrm{rV} 1 i}(t)\right] b_{\mathrm{r}}-F_{\mathrm{rL} i}(t) a_{\mathrm{r}} \\
M_{\mathrm{w} j}(t)=Q_{j}(t) h_{\mathrm{r}}-P_{j}(t) e_{\mathrm{r}} .
\end{array}\right.
$$

Then, the rail displacement can be finally described as

$$
\left\{\begin{array}{l}
z_{\mathrm{r}}(x, t)=\sum_{k=1}^{N_{\mathrm{Z}}} Z_{k}(x) q_{z k}(t), \\
y_{\mathrm{r}}(x, t)=\sum_{k=1}^{N_{\mathrm{Y}}} Y_{k}(x) q_{y k}(t), \\
\phi_{\mathrm{r}}(x, t)=\sum_{k=1}^{N_{\mathrm{T}}} \Phi_{k}(x) q_{t k}(t) .
\end{array}\right.
$$

Further, the dynamic moments of the rail can be expressed by

$$
\left\{\begin{array}{l}
M_{z}=E I_{y} \frac{\partial^{2} z_{\mathrm{r}}(x, t)}{\partial x^{2}}, \\
M_{y}=E I_{z} \frac{\partial^{2} y_{\mathrm{r}}(x, t)}{\partial x^{2}} .
\end{array}\right.
$$

When trains are running through, the rail bottom suffers from tensile stress while rail top suffers from compressive stress. Hence, the tensile stress of rail bottom should be paid attention to, which is written as

$$
\left\{\begin{array}{c}
\sigma_{\mathrm{d} z}=\frac{M_{z}}{W_{\mathrm{r}}} \\
\sigma_{\mathrm{d} y}=\frac{M_{y}}{W_{\mathrm{r}}}
\end{array}\right.
$$

However, the maximum dynamic stress of the edge of the rail bottom $\sigma_{\mathrm{d}}$ is the superposition of $\sigma_{\mathrm{d} z}$ and $\sigma_{\mathrm{d} y}$.

2.2.2. Thermal Stress of Rail. Thermal stress of rail $\sigma_{\mathrm{t}}$ can be divided into two aspects, namely, (a) thermal stress caused by temperature load acting on the rail $\sigma_{\text {tr }}$ and (b) thermal stress caused by temperature load acting on the bridge structure $\sigma_{\mathrm{tb}}$.

The thermal stress $\sigma_{\mathrm{tr}}$ can be calculated by

$$
\sigma_{\mathrm{tr}}=E \alpha \Delta T_{\max }
$$

where $E$ is the elasticity modulus of the rail, which is $2.1 \times 10^{11} \mathrm{~Pa}$; $\alpha$ is the coefficient of linear expansion, which is $1.18 \times 10^{-5} /{ }^{\circ} \mathrm{C}$ for steel; $\Delta T_{\max }$ is the maximum temperature dropping.

Thus, the above equation can be simplified as

$$
\sigma_{\mathrm{tr}}=2.478 \Delta T_{\max }(\mathrm{MPa})
$$

Moreover, $\sigma_{\mathrm{tb}}$. is caused by the difference between rail longitudinal displacement and bridge longitudinal displacement, which can be calculated adopting finite element theory.

The free strain of the bridge caused by temperature difference in the height direction is given by

$$
\varepsilon_{T}(y)=\alpha T_{y},
$$

where $\alpha$ is the coefficient of linear expansion for concrete and $T_{y}$ is the temperature distribution along the height direction.

However, the above free strain is restrained by the strain in the concerned cross-section; thus. the actual strain of the bridge beam caused by temperature is 


$$
\varepsilon(y)=\varepsilon_{0}+\rho y,
$$

where $\varepsilon_{0}$ is the strain of the centroid of the cross section and $\rho$ is the curvature.

On this basis, the strain and stress of the bridge caused by temperature difference are given as

$$
\left\{\begin{array}{l}
\varepsilon_{\sigma}(y)=\varepsilon_{T}(y)-\varepsilon(y)=\alpha_{T}(y)-\left(\varepsilon_{0}+\rho y\right), \\
\sigma_{\varepsilon}(y)=E \varepsilon_{\sigma}(y)=E\left[\alpha_{T}(y)-\left(\varepsilon_{0}+\rho y\right)\right] .
\end{array}\right.
$$

Hence, the bridge deformation induced by temperature effect can be calculated by

$$
\Delta \delta_{n}=B^{-1} \Delta \varepsilon
$$

where $B$ is the element matrix.

With coordinate conversion, the whole bridge displacement can be calculated, as well as the interaction force $F_{\mathrm{r}}$ between the bridge and the rail. On this basis, the thermal stress caused by temperature load acting on the bridge structure can be given by

$$
\sigma_{\mathrm{tb}}=\frac{F_{r}}{A},
$$

where $F_{\mathrm{r}}$ is interaction force between the rail and the bridge and $A$ is the area of cross-section of the rail.

2.2.3. Braking Stress of Rail. Braking stress of the rail $\sigma_{\mathrm{b}}$ is caused by the braking force of the train. The braking force can be calculated by

$$
F_{b}=\varphi \sum K_{h}
$$

where $\varphi$ is the friction factor between the wheel and the rail; $\sum K_{h}$ is the sum of brake shoe forces of the train, which can be determined according to the 'Code for calculation of train traction (TB/T 1407-1998)'. by

Further, the braking stress of the rail is finally calculated

$$
\sigma_{\mathrm{b}}=\frac{F_{b}}{A}
$$

2.2.4. Additional Stress of Rail in CDTWP System. Additional stress of the rail $\sigma_{\mathrm{a}}$ is the most special stress, which obviously exists in the double thin-walled pier system, as seen in Figure 4. When trains are running in different directions on the bridges, the rotation directions of beams are different due to the eccentric train loads. This further results in the sharp deformation of the rail, as well as additional stress of the rail.

Adopting the established train-track-bridge dynamic interaction model, the rail deformation can be determined and the additional stress of the rail $\sigma_{\mathrm{a}}$ can be further calculated employing equations (6) and (7).

2.2.5. Evaluation of Rail Stress. Employing the above method for calculating different kinds of rail stresses, the rail total stress in the CDTWP system can be evaluated, as seen in the following equation:

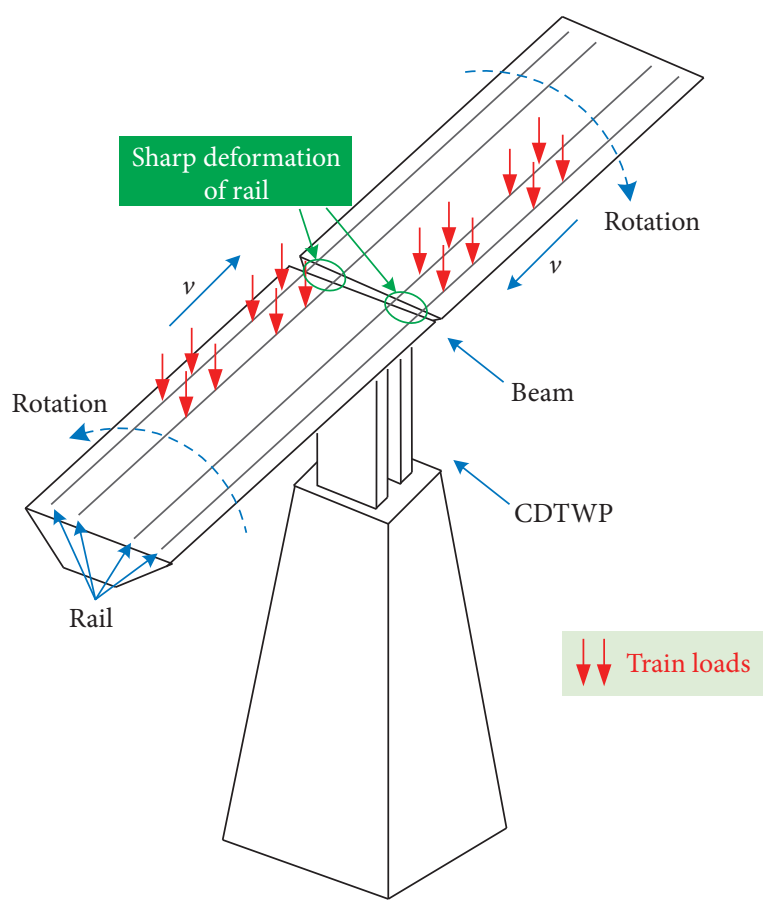

Figure 4: Rotation directions of beams are different due to eccentric train loads.

TABLE 3: Yield strengths of different kinds of steels for the rail.

\begin{tabular}{lc}
\hline Steel & $\begin{array}{c}\text { Yield strength } \\
(\mathrm{MPa})\end{array}$ \\
\hline U71Mn, U71MnG & 457 \\
U75 V, U75VG, U76CrRE, U77MnCr, U78CrV & 472 \\
\hline
\end{tabular}

$$
\sigma_{\mathrm{d}}+\sigma_{\mathrm{t}}+\sigma_{\mathrm{b}}+\sigma_{\mathrm{a}} \leq[\sigma]=\frac{\sigma_{\mathrm{s}}}{K},
$$

where $[\sigma]$ is the allowable stress of the rail, $\sigma_{\mathrm{s}}$ is the yield strength of the rail (listed in Table 3 ), and $K$ is the security coefficient, which is ruled to 1.3 according to the 'Code for Design of Railway Continuous Welded Rail (TB 10015-2012)'.

If the rail total stress exceeds the allowable stress of the rail, the stability and service life of the rail would be greatly influenced, and the longitudinal stiffness of CDTWP should be redesigned to ensure the normal working of rail.

\section{Case Study in Practical Engineering}

A long-span rigid frame bridge with CDTWP is designed in the urban transit in Chongqing, China. The height of the pier is almost $80 \mathrm{~m}$, leading to the size of pier bottom too large, employing the traditional method for determining pier stiffness. This occupies a large area and also affects the beauty of the city. On this basis, the longitudinal stiffness of the CDTWP is analyzed based on the method proposed in this work to design a reasonable size of pier bottom.

3.1. Parameters Adopted in Calculations. The designed rigid frame bridge is shown in Figure 5, in which the length of the pier bottom (denoted by notation ' $w$ ') is the parameter 


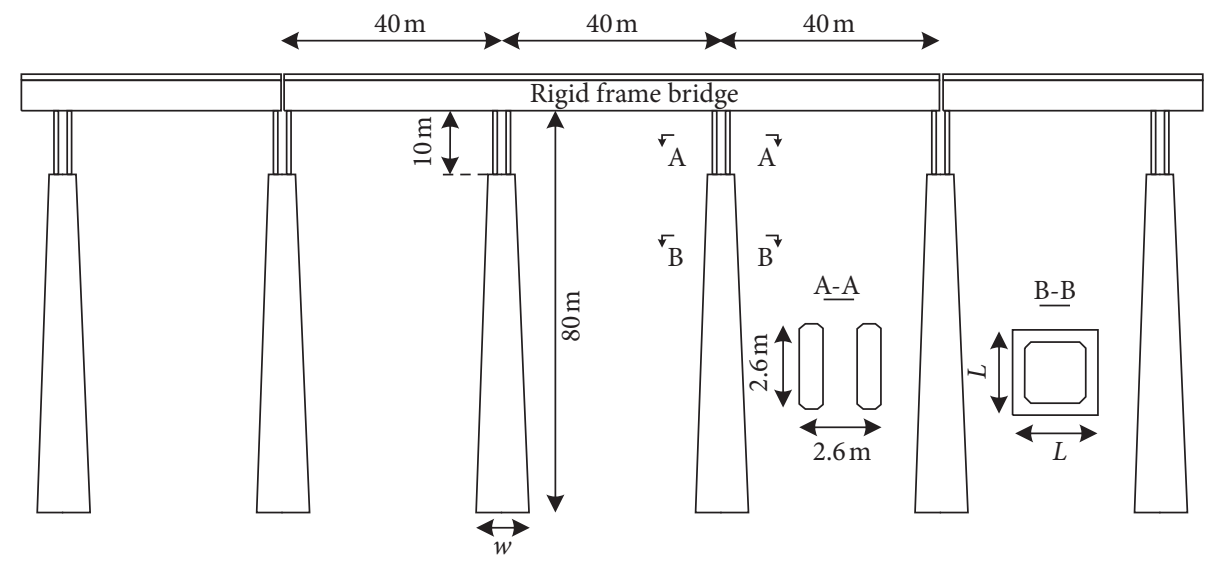

Figure 5: Design of the bridge with CDTWP.

needed to optimize to meet the requirement of operation safety and beauty. The temperature difference for bridge calculation is referred in Table 4 .

The parameters of the adopted track are listed as follows:

(a) The monolithic roadbed track is adopted

(b) The distance between centers of tracks is $5.2 \mathrm{~m}$

(c) The steel type of the rail is $U 75 \mathrm{~V}$, and thus the allowable stress of the rail is $363 \mathrm{MPa}$ according to Table 3 and equation (17)

(d) According to the practical temperature data in Chongqing city, the maximum and minimum rail temperatures are $63^{\circ} \mathrm{C}$ and $-1.8^{\circ} \mathrm{C}$ and the locked rail temperature is $31^{\circ} \mathrm{C}$

(e) The fastener spacing is $595 \mathrm{~mm}$, and the longitudinal resistance of each fastener is $7 \mathrm{kN}$

The type A metro train is adopted, whose dynamic parameters can be found in the published reference [15]. The braking friction coefficient between the wheel and the rail is set to be 0.25 .

\subsection{Determined Longitudinal Stiffness of CDTWP.} Adopting the established method and parameters, the longitudinal stiffness of CDTWP is determined in this section.

The rail total stress in the CDTWP system is illustrated in Figure 6. As seen from the results, the dynamic stress of the rail bottom is not sensitive to the size of the pier bottom, indicating that the size of the pier has almost no influence on the vertical and lateral dynamic displacements of rails. Also, the thermal stress caused by applying temperature load on the rail does not change with $w$, while that caused by temperature load applied on the bridge structure changes sharply with the size of the pier bottom, indicating that the thermal deformation of the bridge system indeed has a great influence on the mechanical performance of the track structure. Moreover, the braking stress and additional stress of the rail obviously change with $w$. With the decrease of the size of the pier bottom (the decrease of pier longitudinal stiffness), the total stiffness of the track-bridge
TABLE 4: Temperature difference for the bridge ruled in 'Code for Design of Railway Continuous Welded Rail (TB 10015-2012)'.

\begin{tabular}{lcc}
\hline \multirow{2}{*}{ Bridge type } & \multicolumn{2}{c}{ Temperature difference } \\
& Ballasted track $\left({ }^{\circ} \mathrm{C}\right)$ & Ballastless track \\
\hline Concrete bridge & 15 & $30^{\circ} \mathrm{C}$ \\
Steel bridge & 25 & - \\
\hline
\end{tabular}

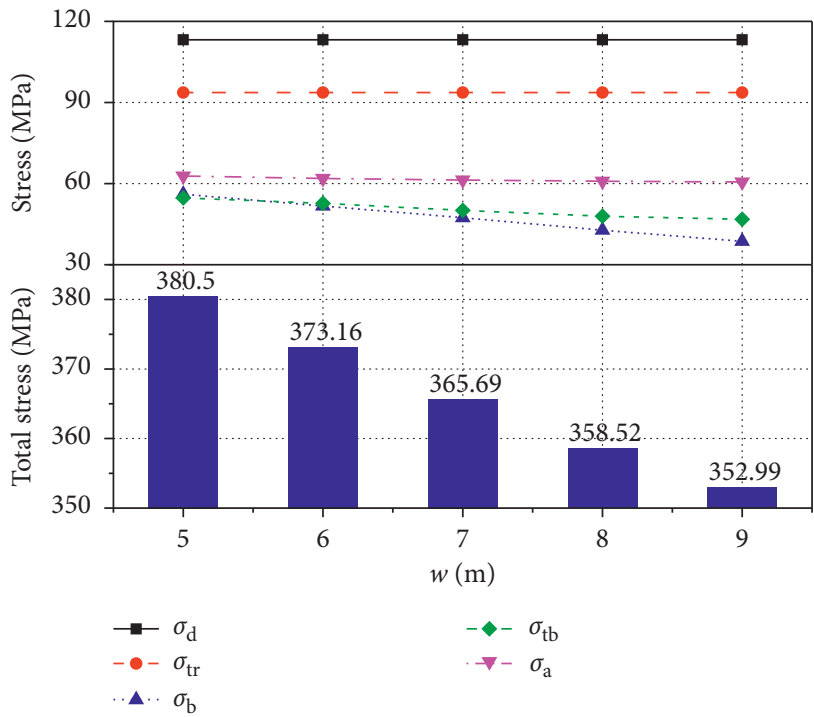

FIgURE 6: Rail stress in the CDTWP system.

system decreases, which further results in sharply tensile deformation of the rail. Hence, the increment of pier longitudinal stiffness can signally reduce the force applied on the rail.

Among different kinds of stresses, the amplitudes of dynamic stress and thermal stress are the largest two, while the influences of other stresses are relatively smaller. Additionally, as seen from the bar graph in Figure 6, the total stress exceeds the allowable stress of the rail with the decrease of $w$. Thus, $w$ should be larger than $7 \mathrm{~m}$ from the perspective of rail stress. 


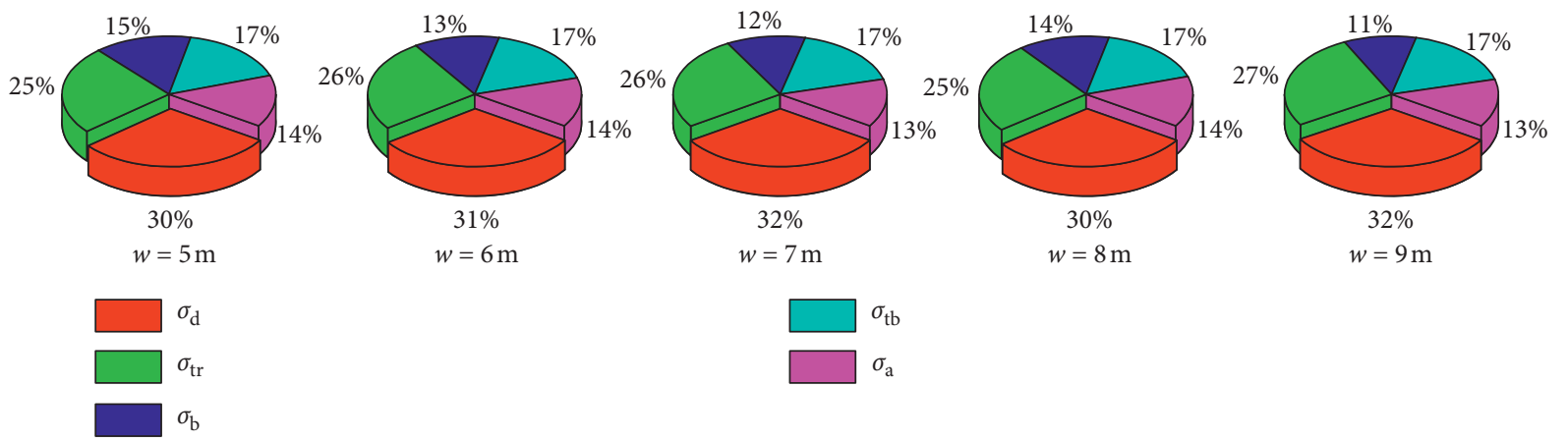

Figure 7: Proportions of different stress among total stress.

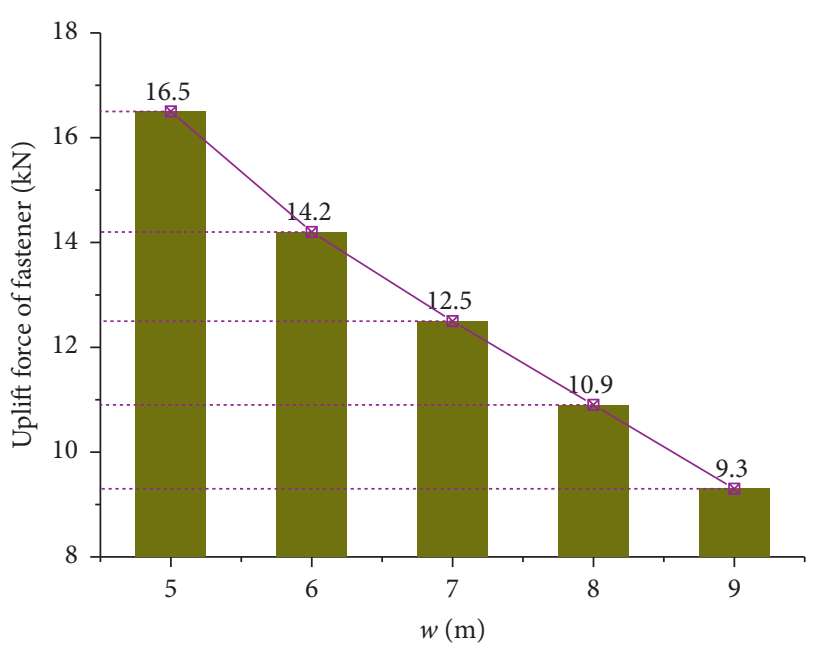

Figure 8: Uplift forces of fasteners with different $w$.

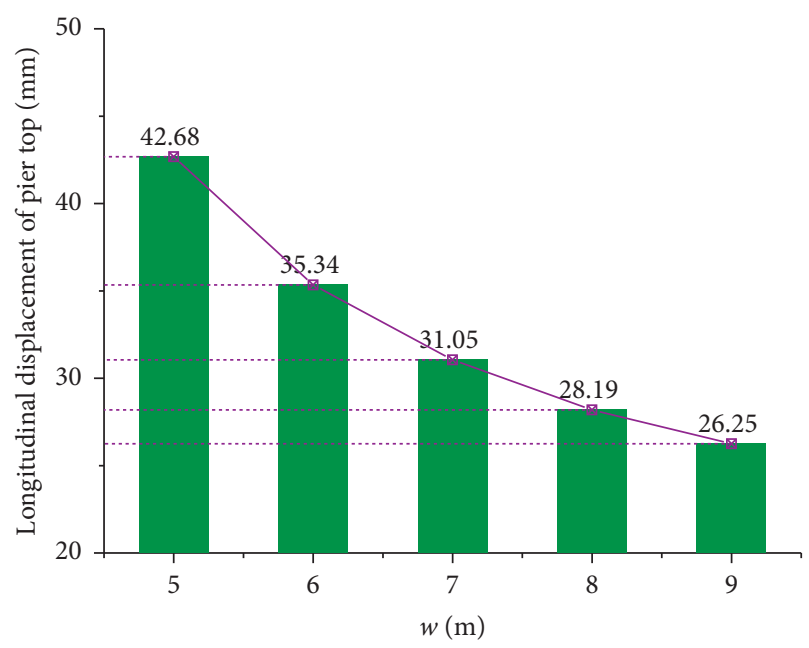

Figure 9: Pier longitudinal displacement with different $w$.

Further, the proportions of different stress among the total stress are shown in Figure 7. As seen from the results, the proportion of dynamic stress occupies about $30 \%$ and the braking stress occupies the least proportion.

It should be noted that fasteners restrain the movement of rails. If rails deform a lot, the uplift forces of fasteners may

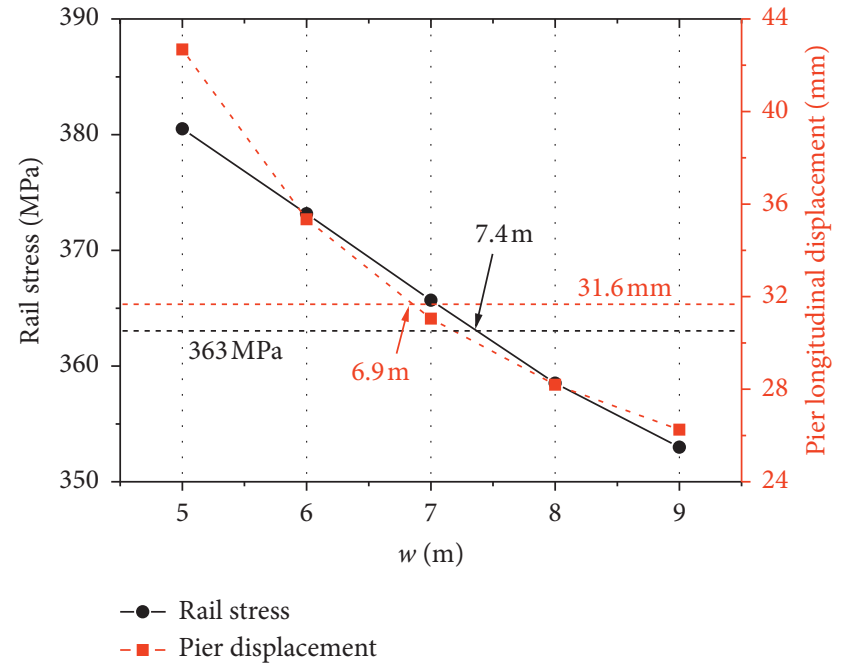

FIgURE 10: Suggested $w$ for the designed bridge.

also exceed the limit. Figure 8 displays the uplift forces of fasteners with different $w$. The maximum uplift force of a fastener is $16.5 \mathrm{kN}$, which does not exceed the limit value according to the 'Code for Design of Railway Continuous Welded Rail (TB 10015-2012)', indicating that the normal working of the fastener system can be ensured.

Moreover, the LSP direction affects the longitudinal displacement of the pier top, thus the longitudinal displacement of the pier top with different $w$ is shown in Figure 9. The calculated pier displacement is caused by thermal effect, train load, and braking load. With the increase in $w$, the pier displacement decreases nonlinearly. The limit value for the pier longitudinal displacement is $31.6 \mathrm{~mm}$, indicating that $w$ should be larger than $6 \mathrm{~m}$ from the perspective of the pier top longitudinal displacement.

As seen from the above calculations, rail stress and pier longitudinal displacement exceed the limits with the decrease of $w$. Figure 10 shows the suggested $w$ for the designed bridge. The length of the pier bottom is finally suggested to be larger than $7.4 \mathrm{~m}$ to ensure the operation safety of the system.

\section{Conclusion}

This work has proposed a novel method for determining the longitudinal stiffness of CDTWP based on the train-track- 
bridge interaction. Primarily, the relationship between longitudinal stiffness of CDTWP and rail stress has been underlined, based on which the proposed methodology has been described in detail. Adopting the presented method, a numerical case has been conducted to validate the effectiveness of the proposed method. Some interesting conclusions have been drawn as follows:

(1) Train-track-bridge dynamic interaction theory is effective in determining the longitudinal stiffness of the newly designed and special pier.

(2) The dynamic stress and thermal stress of the rail are the two most important indicators in determining LSP, which should be paid attention to in practical engineering.

(3) Rail stress and longitudinal displacement of the pier top exceed the limit values with the change of LSP. For the engineering problem solved in this work, the suggested length of the pier bottom should be larger than $7.4 \mathrm{~m}$ to ensure the safe operation and beauty of the city.

\section{Data Availability}

No data were used to support this study.

\section{Conflicts of Interest}

The authors declare that they have no conflicts of interest.

\section{Acknowledgments}

This work was supported by the Basic Natural Science and Frontier Technology Research Program of the Chongqing Municipal Science and Technology Commission (grant numbers: cstc2019jcyj-msxmX0777 and cstc2018jcyjAX0271), the State Grid Chongqing Electric Power Company Zikong Science and Technology Project (grant number: 2020-01), the Science and Technology Research Program of Chongqing Municipal Education Commission (grant number: KJQN201900719), the China Postdoctoral Science Foundation (grant number: 2019M650236), the Open Research Fund of Chongqing Key Laboratory of Railway Vehicle System Integration and Control (grant number: CKLURTSIC-KFKT-201804), and the Project of Fund Cultivation of Chongqing Jiaotong University (grant number: 2018PY14).

\section{References}

[1] M. T. A. Chaudhary, "Influence of Pier Stiffness Degradation on soil-structure interaction in base-isolated bridges," Journal of Bridge Engineering, vol. 9, no. 3, pp. 287-296, 2014.

[2] L. Chen, J. Li, and W. Zhang, "Effects of girder and pier stiffness on continuous bridge regularity in transverse direction," Journal of Tongji University, vol. 35, no. 9, p. 1175, 2007.

[3] A. W. Stuedlein and D. H. Robert, "Analysis of footing load tests on aggregate pier reinforced clay," Journal of
Geotechnical and Geoenvironmental Engineering, vol. 138, pp. 1091-1103, 2011.

[4] S. S. Wei, "Effects of pier stiffness on the seismic response of continuous bridges with irregular configuration," Applied Mechanics and Materials, vol. 638-640, pp. 1794-1802, 2014.

[5] H. Roh, Y.-C. Ou, J. Kim, and W. Kim, "Effect of yielding level and post-yielding stiffness ratio of ED bars on seismic performance of PT rocking bridge piers," Engineering Structures, vol. 81, pp. 454-463, 2014.

[6] H.-h. Yuan, Q.-x. Wu, Y.-f. Huang, and Z.-m. She, "Experimental and theoretical studies on the seismic performance of CFST battened built-up column piers," Engineering Structures, vol. 206, p. 110099, 2020.

[7] P. Shen, J. Han, J. G. Zornberg et al., "Two and three-dimensional numerical analyses of geosynthetic-reinforced soil (GRS) piers," Geotextiles and Geomembranes, vol. 47, no. 3, pp. 352-368, 2019.

[8] M. Pollino and M. Bruneau, "Seismic testing of a bridge steel truss pier designed for controlled rocking," Journal of Structural Engineering, vol. 136, no. 12, pp. 1523-1532, 2010.

[9] J. M. Olmos and M. A. Astiz, "Analysis of the lateral dynamic response of high pier viaducts under high-speed train travel," Engineering Structures, vol. 56, pp. 1384-1401, 2013.

[10] Y. Huang, B. Briseghella, T. Zordan, Q. Wu, and B. Chen, "Shaking table tests for the evaluation of the seismic performance of an innovative lightweight bridge with CFST composite truss girder and lattice pier," Engineering Structures, vol. 75, pp. 73-86, 2014.

[11] X. Chen, Z. Guan, B. F. Spencer Jr, and J. Li, “A simplified procedure for estimating nonlinear seismic demand of tall piers," Engineering Structures, vol. 174, pp. 778-791, 2018.

[12] L. Xu, Z. Yu, and C. Shi, "A matrix coupled model for vehicleslab track-subgrade interactions at 3-D space," Soil Dynamics and Earthquake Engineering, vol. 128, Article ID 105894, 2020.

[13] Z. Chen, Z. Han, W. Zhai, and J. Yang, "TMD design for seismic vibration control of high-pier bridges in SichuanTibet Railway and its influence on running trains," Vehicle System Dynamics, vol. 57, no. 2, pp. 207-225, 2019.

[14] Z. Chen, H. Fang, Z. Han, and S. Sun, "Influence of bridgebased designed TMD on running trains," Journal of Vibration and Control, vol. 25, no. 1, pp. 182-193, 2019.

[15] Z. Chen and W. Zhai, "Theoretical method of determining pier settlement limit value for China's high-speed railway bridges considering complete factors," Engineering Structures, vol. 209, p. 109998, 2020. 